\title{
Combined Long-Term Steroid and Immunosuppressive Treatment Regimen in Granulomatous Mastitis
}

\author{
Ali Konan ${ }^{a} \quad$ Umut Kalyoncu $^{\mathrm{b}}$ Ismail Dogan ${ }^{\mathrm{b}}$ Yusuf A. Kılıç $^{\mathrm{a}}$ Derya Karakoç $^{\mathrm{a}}$ \\ Ali Akdogan ${ }^{\mathrm{b}}$ Sedat Kiraz $^{\mathrm{b}}$ Volkan Kaynaroğlu $^{\mathrm{a}}$ Demirali Onat $^{\mathrm{a}}$ \\ aDepartment of General Surgery, \\ ${ }^{b}$ Department of Internal Medicine, Division of Rheumatology, Faculty of Medicine, Hacettepe University, Ankara, Turkey
}

\section{Keywords}

Granulomatous mastitis, idiopathic · Corticosteroids . Azathioprine

\section{Summary}

Background: Idiopathic granulomatous mastitis (IGM) is a rare benign inflammatory disease of the breast. It is related to various etiological factors. The treatment of IGM is challenging as there is a lack of consensus in the literature and treatment options vary widely. Conservative treatment with antibiotics, glucocorticoids and immunosuppressive drugs, and surgery are used in the management of the disease. In this article we report our experience with IGM patients receiving immunosuppressive treatment. Patients and Methods: The medical records of patients with IGM receiving systemic therapy at the Hacettepe University Hospital between October 2007 and May 2010 were reviewed. 15 cases of histopathologically proven IGM were identified. The data was examined for risk factors and success of treatment. Results: 14 patients were given prednisolone together with azathioprine, and 1 patient who was pregnant at the time of diagnosis received only prednisolone (30 mg/day). $11(73 \%)$ patients had a complete response to systemic therapy. 2 patients had a relapse, of whom 1 required surgical drainage and 1 was treated with a higher dose of glucocorticoids. Conclusion: Systemic therapy is a safe and effective treatment for IGM. The addition of azathioprine to glucocorticoid therapy permits quick tapering of the steroid doses and increases the treatment success.

\author{
Schlüsselwörter \\ Granulomatöse Mastitis, idiopathische . \\ Kortikosteroide · Azathioprin
}

\section{Zusammenfassung}

Hintergrund: Die idiopathische granulomatöse Mastitis (IGM) ist eine seltene, gutartige, entzündliche Erkrankung der Brust, an deren Entstehung verschiedene ätiologische Faktoren beteiligt sind. Die Behandlung der IGM stellt auf Grund eines mangelnden Konsens in der Literatur und breit gefächerten Therapieansätzen eine Herausforderung dar. Neben der chirurgischen Behandlung kommen konservative Therapien mit Antibiotika, Glukokortikoiden und Immunsuppressiva zum Einsatz. Wir berichten von unseren Erfahrungen mit IGM-Patienten, die mit immunsuppressiver Therapie behandelt wurden. Patientinnen und Methoden: Die Behandlungsunterlagen von IGM-Patientinnen, die zwischen Oktober 2007 und Mai 2010 am Hacettepe University Hospital systemische Therapie erhielten, wurden begutachtet. 15 Fälle von histopathologisch bestätigter IGM konnten identifiziert werden. Die Daten wurden hinsichtlich Risikofaktoren und Behandlungserfolg geprüft. Ergebnisse: 14 Patientinnen wurden mit Prednisolon kombiniert mit Azathioprin behandelt. Eine Patientin, die zum Diagnosezeitpunkt schwanger war, erhielt ausschließlich Prednisolon (30 mg/d). 11 (73\%) Patientinnen zeigten ein komplettes Ansprechen auf die systemische Therapie. 2 Patientinnen entwickelten ein Rezidiv, welches in einem Fall chirurgische Drainage erforderte und in einem Fall mit einer höheren Glukokortikoiddosis behandelt werden konnte. Schlussfolgerung: Die systemische Therapie zur Behandlung der IGM ist sicher und effektiv. Der Zusatz von Azathioprin zur Glukokortikoid-Therapie erlaubt eine schnellere Reduktion der Steroiddosis und erhöht den Behandlungserfolg.

\section{KARGER \\ Fax +497614520714 \\ Information@Karger.de}

www.karger.com (c) 2012 S. Karger GmbH, Freiburg

$1661-3791 / 12 / 0074-0297 \$ 38.00 / 0$

Accessible online at:

www.karger.com/brc
Ali Konan M.D., Ph. D.

Hacettepe Universitesi Tıp Fakültesi

Genel Cerrahi Anabilim Dalı

Gevher Nesibe Cad., Sihhiye Ankara Türkiye

Tel. +903123051676

akonan@hacettepe.edu.t 


\section{Introduction}

Granulomatous mastitis is a rare benign inflammatory disease of the breast. It is related to various etiological factors such as tuberculosis, sarcoidosis, foreign body reactions, and fungal infections [1]. The disease is accepted to be idiopathic after exclusion of all infectious and non-infectious causes of granulomatous disease. Idiopathic granulomatous mastitis (IGM) must be differentiated from inflammatory carcinoma of the breast as clinical features may be very similar [2-4]. The pathophysiology of the disease remains unknown. Recent reports claim a relationship between corynebacterium infection and IGM [5-7]. IGM typically affects women of childbearing age, and most patients have a recent history of breast feeding [8]. Retention of intraductal secretions causing localized immune response to extravasated protein and fat-rich secretions into the duct is proposed as an initiating factor. The treatment of IGM is challenging as there is a lack of consensus in the literature and treatment options vary widely [9]. There are several reports on surgery and conservative treatment including glucocorticoids and immunosuppressive drugs for the management of the disease [10-16]. The recurrence rate of surgical treatment is high, and response rates to steroid treat-

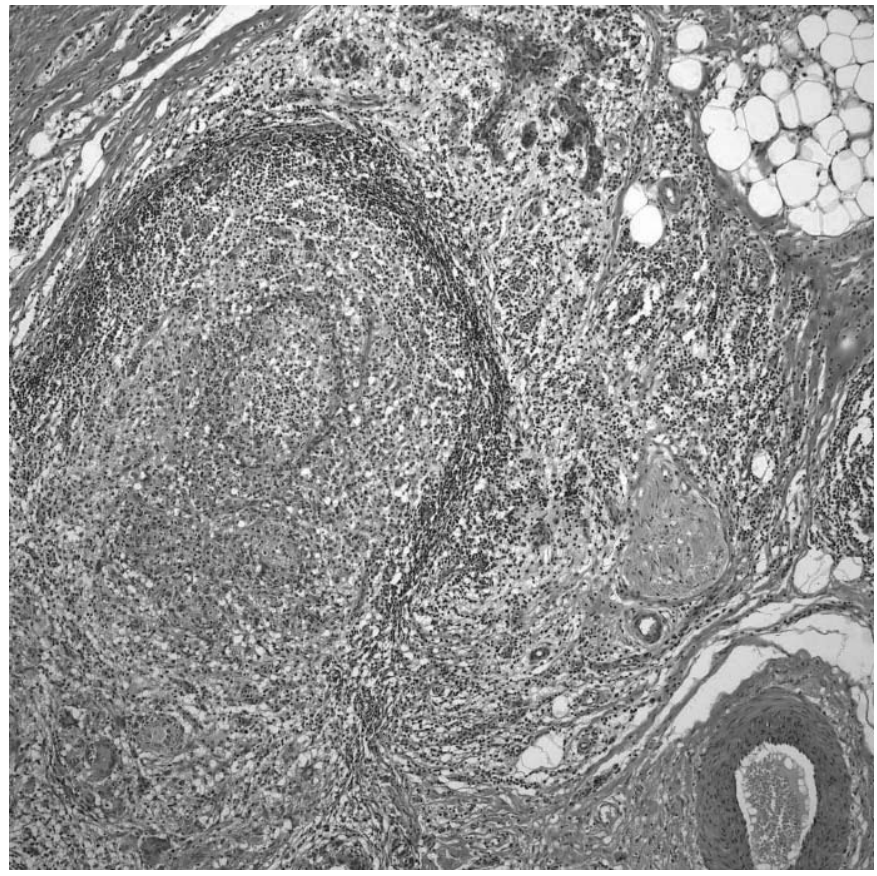

Fig. 1. Histopathologic appearance of granulomatous mastitis.

Table 1. Physical examination findings of the patients $(n=15)$

\begin{tabular}{ll}
\hline Symptom/clinical sign & \\
\hline Largest diameter of the mass ${ }^{\mathrm{a}}, \mathrm{cm}$ & $5.46 \pm 2.99$ \\
Axillary lymphadenopathy, n (\%) & $4(26.7)$ \\
Fistula formation, n (\%) & $4(26.7)$ \\
Erythema/cellulitis, n (\%) & $6(40)$ \\
Ulceration, n (\%) & $1(6.6)$ \\
\hline
\end{tabular}

${ }^{\mathrm{a}}$ Mean \pm standard deviation. ment are low [9]. Immunosuppressives such as methotrexate may be added to the therapy to decrease steroid doses or to treat recurrences $[17,18]$. In this article we report our experience with IGM patients receiving immunosuppressive treatment.

\section{Methods}

The medical records of patients with IGM receiving systemic therapy at the Hacettepe University Hospital between October 2007 and May 2010 were reviewed. 15 cases of histopathologically proven IGM were identified. At the Rheumatology Clinic of our hospital, azathioprine was already being used as a steroid-sparing agent in patients with sarcoidosis, and after a case report by Raj et al. [18] we also started using this drug in IGM. After imaging studies were completed, tissue samples were obtained by open biopsy in 14 patients and by core biopsy in 1 patient. Slides were examined using hematoxylin-eosin and Ziehl-Neelsen for acid fast bacilli (fig. 1). Tissue cultures were tested for presence of tuberculosis and underwent bacteriological evaluation. Chest radiography and tuberculin skin test were assessed prior to steroid treatment. Laboratory data such as erythrocyte sedimentation rate (ESR), C-reactive protein (CRP), anti-neutrophil cytoplasmic antibodies (ANCA), anti-nuclear antibodies (ANA), anti-ro/SSA, anti-double stranded DNA antibodies, and antismooth muscle antibodies were derived from the patients' medical records. All patients were treated with $40-60 \mathrm{mg} /$ day prednisolone for 1 month. Then the prednisolone dosage was tapered to $30 \mathrm{mg} /$ alternate day over a period of 1-2 months, and after 6 months the dosage was 10-15 mg/alternate day. The maintenance dosage of prednisolone was $5-7.5 \mathrm{mg} /$ alternate day. Steroid was stopped after 1.5-2 years. In the case of relapse, the dosage was increased to $40 \mathrm{mg} / \mathrm{day}$. 14 of the patients were treated with $2 \mathrm{mg} / \mathrm{kg} / \mathrm{day}$ azathioprine as steroid-sparing agent. The data was examined for risk factors and treatment success.

\section{Results}

All patients were women. The mean age at diagnosis was 36 years (range 23-49 years). 4 patients had had a child within the past 5 years, 3 patients had no history of pregnancy. 1 patient was pregnant at the time of diagnosis. None of the patients had a history of oral contraceptive use. 4 patients had a concomitant disease ( 2 erythema nodosum, 1 prolactinoma, 1 chronic schizophrenia). The patient with prolactinoma was operated on after initiation of treatment for IGM.

The main complaint at admission was an ill-defined mass in 7 patients and an inflammatory process in 4. A further 4 patients were complaining of both a mass and inflammation. Upon physical examination a painful, ill-defined mass was palpated in 13 of the 15 patients, ranging in size from 2 to $12 \mathrm{~cm}$ in diameter. Axillary lymphadenopathy was present in 5 patients. Physical examination findings are given in table 1 . The clinical impression after physical examination was malignancy in 7 patients, abscess in 7 , and ductal ectasia in 1 patient. Ultrasonography of the breast was performed in 12 patients; 7 (58\%) patients were diagnosed with granulomatous mastitis, $3(25 \%)$ patients with an abscess, and 2 (17\%) patients with cystic disease. Mammography was performed in 
8 patients diagnosing granulamatous mastitis correctly in $2(25 \%)$ and showing asymmetrical density in $4(50 \%)$ patients; results were negative in 2 patients. Magnetic resonance imaging (MRI) studies were performed in 1 patient who was reported to have benign nodules. All except 1 patient underwent open biopsy; 1 patient had a core biopsy. Histopathology confirmed the diagnosis in all patients. During open biopsy, tissue samples were sent for culture and bacteriological examination. 4 patients had positive cultures (1 with both staphylococcus haemolyticus and acinetobacter baumannii, 2 with only streptococcus species, and 1 with serratia marcescens). Tuberculosis was excluded in all patients via tissue culture and polymerase chain reaction (PCR). Elevated serum CRP levels $(>0.8 \mathrm{mg} / \mathrm{dl})$ and ESR $(>20 \mathrm{~mm} / \mathrm{h})$ were observed in 53 and $47 \%$ of patients, respectively.

A total of 14 patients were given prednisolone together with azathioprine. 1 patient who was pregnant at the time of diagnosis received only prednisolone (30 mg/day). Another patient who became pregnant 1 month after the initiation of therapy showed a complete response, so therapy was stopped and no recurrence was observed. There were no adverse events related to azathioprine such as cytopenia, liver dysfunction, or severe infection. 4 of the 15 patients had temporary steroid-induced diabetes mellitus.

All patients were re-examined within 3 months of therapy, and then at 6-month intervals. Median time of follow-up was 26 months (range 7-36 months). At the third month 11 patients showed at least $50 \%$ shrinkage in the size of the tumor. These patients had complete resolution at the 6th month. 2 patients had recurrences in the 4th and the 12th month, respectively, of whom 1 required surgical drainage and the other was treated with a higher dose of steroids. 2 patients had a partial response on follow-up, with a decrease in lesion size. No surgical intervention was required.

\section{Discussion}

IGM is a benign disease of the breast, which mimics malignancy. The diagnosis is sometimes difficult, and no consensus exists on the treatment as there are no prospective studies. The retrospective case series usually have small numbers of patients, the largest being published from Brunei presenting the experience with 43 patients [19]. Most of the reports come from developing countries; this may be due to ethnicity or misdiagnosis of tuberculous mastitis as tuberculosis tends to be more common in these parts of the world [20]. Work-up to rule out tuberculosis should be included in the differential diagnosis of granulomatous mastitis [21]. Tuberculosis was excluded in all our patients via tissue culture and PCR.

The etiology of IGM is unclear. Some mechanisms proposed in the literature include a chemical reaction associated with oral contraceptive use, an underlying autoimmune process, an infectious process that cannot be detected by current

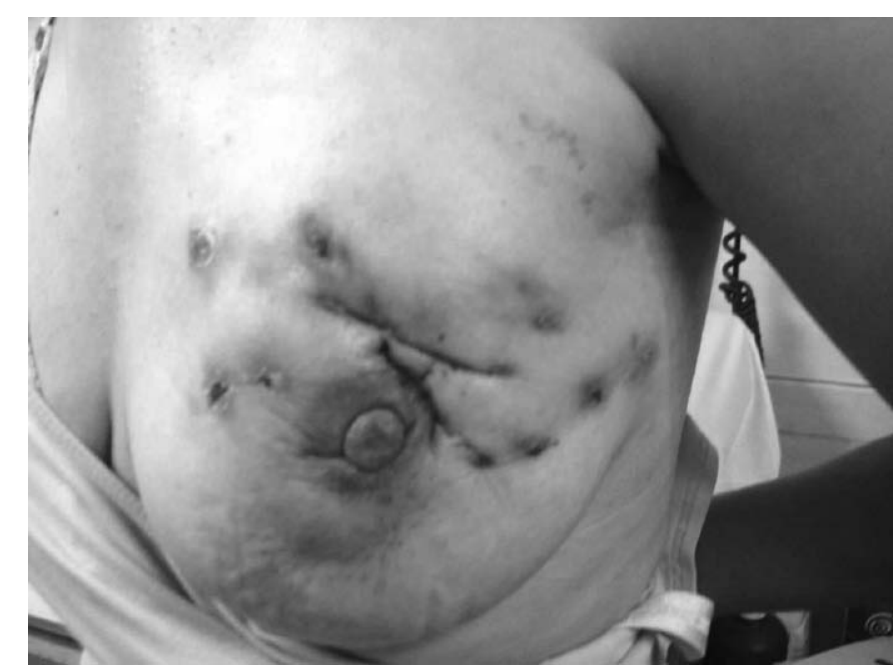

Fig. 2. Non-healing wounds and fistula formation in a patient with granulomatous mastitis..

Table 2. Treatment regimens used for granulomatous mastitis patients

\begin{tabular}{lll}
\hline Time & Target steroid dose $^{\mathrm{a}}$ & Azathioprine scheme \\
\hline Baseline & $40-60 \mathrm{mg} /$ day & $150 \mathrm{mg} / \mathrm{day}$ \\
1-2 months & $30 \mathrm{mg}$ every other day & $150 \mathrm{mg} / \mathrm{day}$ \\
6 months & $10-15 \mathrm{mg}$ every other day & $100-150 \mathrm{mg} /$ day \\
6-24 months & $5-7.5 \mathrm{mg}$ every other day & $50-100 \mathrm{mg} /$ day \\
\hline
\end{tabular}

a Steroid dose tapered to achieve given target doses.

means, or an immune response to extravasated secretions from the lobules [20]. Non-puerperal secretion in the ducts and extravasation of the intraductal components are proposed as the initiating factor. Lactation, prolactinomas, and drugs increasing intraductal secretion (e.g. anti-psychotics) can cause intraductal accumulation of the products of secretion. IGM associated with breast feeding tends to be more severe and lasts longer [22]. In our series, 1 patient was pregnant at the time of diagnosis so she was treated only with steroids; 1 patient who was diagnosed as having prolactinoma after the initiation of therapy had a partial recovery and was operated on 1 year later. 1 patient was diagnosed as having schizophrenia and was using anti-psychotic drugs. 2 patients had only a partial response to treatment. In treatment-refractory cases these risk factors should be taken into account. Corynebacterium infection is also proposed as an initiating factor, but this is not supported by our series as none of the isolated microorganisms were corynebacteria.

Radiologic imaging methods such as mammography, ultrasonography, and MRI present a wide spectrum of findings and are inconclusive in the differentiation between malignant and benign conditions in patients with IGM [23]. Mammography may show focal asymmetric density in $50 \%$ of patients, and less frequently irregular masses, axillary lymphadenopathy, or skin thickening may be observed [24]. Ultrasonography on the other hand may identify a lesion in every patient. Although the findings are not specific to the disease, 
most frequently, an irregular hypoechoic mass with multiple tubular hypoechoic structures is seen on ultrasonography. In our series, all imaging studies were performed by the Breast Imaging Subdivision of the Radiology Department of our hospital, and ultrasonography led to suspicion of granulomatous mastitis in $58 \%$ of the patients. More importantly, when performed by the same team, ultrasonography is a useful tool in the follow-up of patients with a partial response to therapy. With increasing experience in imaging studies, some cases of IGM may be diagnosed by less invasive methods of biopsy, but tissue sampling is always necessary to establish the diagnosis and rule out tuberculosis.

The main concern with IGM is ruling out malignancy. In our series 11 of the 15 patients presented with a mass with or without inflammation, and in half of the patients the initial impression was that of malignancy. All except 1 patient underwent open biopsy. Various techniques of biopsy are used in the diagnosis of IGM. Fine needle aspiration biopsy is the least invasive method but can yield confusing results which often necessitate confirmation by open biopsy [25, 26]. Core biopsy is used in small case series with a good success rate. About half of the patients with IGM have an abscess that requires open drainage; in such cases biopsies from the abscess wall are helpful in the diagnosis. We consider open biopsy to be the safest method to rule out malignancy.

Wilson et al. [9] analyzed 116 cases of IGM published in the literature and reviewed the treatment methods. They showed that the most commonly used approach is wide excision of the affected area with a success rate of $79 \%$. Ocal et al. [8] treated 16 IGM patients with surgery; 4 patients required quadrantectomy, and $75 \%$ of the patients needed reoperation either for completion of the excision after surgical drainage or for recurrence. In the largest series in the literature, Kok and Telisinghe [19] performed surgical therapy on 40 of 43 patients with IGM. 10 (23\%) of the patients had recurrences which were again treated with surgery; this patient group experienced 2 further recurrences. The high incidence of recurrence necessitates extensive resection to obtain disease-free margins. Wound complications are an important issue in the surgical treatment of IGM. Repeated incisions which often fail to heal make the cosmetic outcome unacceptable. Figure 2 shows a patient with multiple incisions and fistulae before the initiation of systemic therapy. Wide local excision to obtain disease-free margins or mastectomy for benign disease is a challenging decision both for the surgeon and the patient. Breast reconstruction techniques may be used to improve patient satisfaction [12]. The cosmetic results of the surgery are very poor, and the addition of systemic therapy may prevent surgical intervention for recurrences.

There are few reports on systemic treatment in IGM. Azlina et al. [14] administered $60 \mathrm{mg}$ /day prednisolone to 12 patients and reported a $50 \%$ recurrence rate after a short 4-week course of therapy. They also administered a second course of steroids for recurrences after which complete resolution was noted, and concluded that the steroid therapy should last longer. In their series of 9 patients, Lai et al. [10] stated that half of the patients had spontaneous resolution of the disease within 2 years, and the other half had stable disease. This may demonstrate the self-limiting aspect of the disease. In our clinic, we prefer to start with high-dose steroid therapy which is gradually tapered down and then switched to alternate days as soon as possible to avoid long-term side effects and continued for at least 2 years at the lowest dose tier (table 2). So far, we have not observed major steroidrelated side effects except temporary steroid-induced diabetes mellitus.

IGM usually presents in 2 forms; either as a painful mass or as a breast abscess. The abscess is reported to be sterile in most series. In our series 4 patients had positive pus cultures suggesting secondary infection. As steroid therapy causes immunosuppression, it is not safe to start glucocorticoids in the presence of a bacterial infection. These patients needed antibiotic therapy, and steroid therapy was started after the signs of infection had subsided.

Kim et al. [17] first reported the use of methotrexate together with steroids in 4 women with IGM, which was started after excisional biopsy. Steroid therapy was stopped after 1 year, and methotrexate was continued for another 3-6 months. None of their patients had recurrences under the medical therapy, but after cessation of methotrexate 2 relapses occurred. Raj et al. [18] also reported 2 successfully treated cases. As mentioned previously, in their paper they also report on a patient treated with azathioprine. Azathioprine is an immunosuppressive drug which is widely used as a steroid-sparing agent after the initial control of autoimmune disease. It is administered orally and metabolized intracellularly to a purine antagonist and inhibits both cellular and humoral immunity by reducing the number of $\mathrm{T}, \mathrm{B}$, and natural killer cells; furthermore it suppresses autoantibody formation and inhibits prostaglandin synthesis. It is indicated mainly as an anti-rejection drug for organ transplants but also in many autoimmune diseases such as lupus, rheumatoid arthritis, sarcoidosis, autoimmune liver disease, and Behcet's syndrome.

Although benign and self-limiting by nature, IGM is a disease which alters the daily life of the patient. Repeated operations are stressful for the patient and the surgeon, and the cosmetic outcome of the surgical treatment is often unsatisfactory with scarring and fistula formation. Our case series with 14 patients receiving systemic immunosuppressive therapy is the largest in the literature so far. This series suggests azathioprine is a good choice in the treatment of IGM. Complete remission was observed in $71 \%$ of the patients, and only 1 patient (7\%) required surgical intervention during systemic therapy. Overall $93 \%$ of the patients observed for a median of 26 months did not require surgical intervention in the follow-up period. 


\section{Conclusion}

Systemic therapy is safe and effective in the treatment of IGM. The addition of azathioprine to glucocorticoid therapy permits quick tapering of the steroid doses and may increase the success of the therapy. Surgical therapy should be reserved for recurrent cases unresponsive to medical therapy. Larger studies are needed to confirm the results.

\section{Disclosure Statement}

The authors declare no conflict of interest.

\section{References}

1 Miltenburg DM, Speights VO Jr: Benign breast disease. Obstet Gynecol Clin North Am 2008;35:285-300.

2 Marriott DA, Russell J, Grebosky J, Wallace AM, Joste N, Royce ME: Idiopathic granulomatous lobular mastitis masquerading as a breast abscess and breast carcinoma. Am J Clin Oncol 2007;30:564-5.

3 Kessler E, Wolloc Y: Granulomatous mastitis: a lesion clinically simulating carcinoma. Am J Clin Pathol 1972;58:642-6.

4 Tuli R, O'Hara BJ, Hines J, Rosenberg AL: Idiopathic granulomatous mastitis masquerading as carcinoma of the breast: a case report and review of the literature. Int Semin Surg Oncol 2007;4:21.

$\checkmark 5$ Kieffer P, Dukic R, Hueber M, et al.: (A young woman with granulomatous mastitis: a corynebacteria may be involved in the pathogenesis of these disease). Rev Med Interne 2006;27:550-4.

6 Mathelin C, Riegel P, Chenard MP, Tomasetto C, Brettes JP: Granulomatous mastitis and corynebacteria: clinical and pathologic correlations. Breast J 2005;11:357.

7 Mathelin C, Riegel P, Chenard MP, Brettes JP Association of corynebacteria with granulomatous mastitis. Eur J Obstet Gynecol Reprod Biol 2005;119:260-1.

$>8$ Ocal K, Dag A, Turkmenoglu O, Kara T, Seyit H, Konca K: Granulomatous mastitis: clinical, pathological features, and management. Breast J 2010;16:176-82.
9 Wilson JP, Massoll N, Marshall J, Foss RM, Copeland EM, Grobmyer SR: Idiopathic granulomatous mastitis: in search of a therapeutic paradigm. Am Surg 2007;73:798-802.

10 Lai EC, Chan WC, Ma TK, Tang AP, Poon CS, Leong HT: The role of conservative treatment in idiopathic granulomatous mastitis. Breast J 2005; 11:454-6.

11 Asoglu O, Ozmen V, Karanlik H, et al.: Feasibility of surgical management in patients with granulomatous mastitis. Breast J 2005;11:108-14.

12 Taghizadeh R, Shelley OP, Chew BK, WeilerMithoff EM: Idiopathic granulomatous mastitis: surgery, treatment, and reconstruction. Breast J 2007;13:509-13.

13 Akcan A, Akyildiz H, Deneme MA, Akgun H, Aritas Y: Granulomatous lobular mastitis: a complex diagnostic and therapeutic problem. World J Surg 2006;30:1403-9.

14 Azlina AF, Ariza Z, Arni T, Hisham AN: Chronic granulomatous mastitis: diagnostic and therapeutic considerations. World J Surg 2003;27:515-8.

15 Maffini F, Baldini F, Bassi F, Luini A, Viale G: Systemic therapy as a first choice treatment for idiopathic granulomatous mastitis. J Cutan Pathol 2009;36:689-91.

16 Schmajuk G, Genovese MC: First report of idiopathic granulomatous mastitis treated with methotrexate monotherapy. J Rheumatol 2009;36:155960.

17 Kim J, Tymms KE, Buckingham JM: Methotrexate in the management of granulomatous mastitis. ANZ J Surg 2003;73:247-9.
8 Raj N, Macmillan RD, Ellis IO, Deighton CM: Rheumatologists and breasts: immunosuppressive therapy for granulomatous mastitis. Rheumatology (Oxford) 2004;43:1055-6.

19 Kok KY, Telisinghe PU: Granulomatous mastitis: presentation, treatment and outcome in 43 patients. Surgeon 2010;8:197-201.

20 Bani-Hani KE, Yaghan RJ, Matalka II, Shatnawi NJ: Idiopathic granulomatous mastitis: time to avoid unnecessary mastectomies. Breast J 2004; 10:318-22.

21 Ayeva-Derman M, Perrotin F, Lefrancq T, Roy F, Lansac J, Body G: Idiopathic granulomatous mastitis. Review of the literature illustrated by 4 cases. J Gynecol Obstet Biol Reprod (Paris) 1999;28:8007.

22 Al-Khaffaf B, Knox F, Bundred NJ: Idiopathic granulomatous mastitis: a 25-year experience. J Am Coll Surg 2008;206:269-73.

23 Ozturk M, Mavili E, Kahriman G, Akcan AC, Ozturk F: Granulomatous mastitis: radiological findings. Acta Radiol 2007;48:150-5.

24 Hovanessian Larsen LJ, Peyvandi B, Klipfel N, Grant E, Iyengar G: Granulomatous lobular mastitis: imaging, diagnosis, and treatment. AJR Am J Roentgenol 2009;193:574-81.

25 Heer R, Shrimankar J, Griffith CD: Granulomatous mastitis can mimic breast cancer on clinical, radiological or cytological examination: a cautionary tale. Breast 2003;12:283-6.

26 Yip CH, Jayaram G, Swain M: The value of cytology in granulomatous mastitis: a report of 16 cases from Malaysia. Aust N Z J Surg 2000;70:103-5. 